\title{
La gestión de los territorios. La cosecha escondida o la percepción ambiental de los espacios
}

\author{
The Management model of Territories. The hidden harvest or the \\ environmental perception of the spaces
}

\author{
Laura Pérez Prieto* \\ Fecha de recepción: 29-05-2017 - Fecha de aceptación: 10-07-2017 \\ Hábitat y Sociedad (ISSN 2173-125X), n. ${ }^{\circ}$ 10, noviembre de 2017, pp. 349-354. \\ http://dx.doi.org/10.12795/HabitatySociedad.2017.i10.21
}

\begin{abstract}
The book is essentially a multidisciplinary scientific view to move from the current aggressive way we conceive and manage the environmental spaces we live in, to the collective construction of different action plans focused on the harmonic coexistence with everything alive which we depend on. It is clearly structured in four different parts. In the first part (chapters 1 to 4 ), the author establishes the foundations to re-define the relation human beings - nature; re-reads the territory from a contact and interdependence point of view and, she also makes operative the approach of the strong sustainability previously defended over these pages. In the second part (chapters 5 and 6 ) she theoretically develops her methodology of sustainable management of natural resources through significant experiences within the environment and getting back into the common (municipal) spaces. In the third section (chapter 7) she describes down to the last detail, how this quality methodology is included in the pilot project of Agenda 21 just performed for the first time in Isla del Cerrito's municipality, in the province of Chaco, north-east of Argentina. The book is closed with an analysis and conclusions section (chapter 8) on the changes produced in the point of view of the inhabitants and on the contributions of the method to the use of human capacities towards sustainability.
\end{abstract}

\section{Key words}

Sustainability; Management of the territory; Environmental perception; Local action; Agenda 21

\section{Resumen}

El libro es, sobre todo, una propuesta científica interdisciplinar para pasar de la actual forma depredadora de concebir y gestionar los espacios ambientales en los que habitamos, a la construcción colectiva de planes de acción local para la convivencia armónica con la red de todo lo vivo de la que dependemos y formamos parte. Se estructura en torno a 4 partes bien diferenciadas. En la primera parte (del capítulo 1 al 4), la autora sienta las bases para redefinir la relación seres humanos-naturaleza; releer el territorio desde el contacto y la interdependencia; y, operativizar el enfoque de la sustentabilidad fuerte defendido a lo largo de esas páginas. En la segunda parte (capítulos 5 y 6 ) desarrolla teóricamente su propuesta de investigación y su metodología de gestión sustentable de los recursos naturales a través de la generación de experiencias significativas con el medio y la reapropiación de los espacios municipales. En la tercera sección (capítulo 7) describe de forma pormenorizada cómo se incorpora esta metodología cualitativa al proyecto piloto de Agenda 21 que se abre en el municipio de Isla del Cerrito, en la provincia de Chaco, al nordeste de Argentina. El libro se cierra con un apartado de análisis y conclusiones (capítulo 8) sobre los cambios producidos en la mirada de los y las habitantes y sobre las contribuciones del método a la instalación de capacidades humanas hacia la sustentabilidad.

\section{Pallabras clave}

Sustentabilidad; Gestión del territorio; Percepción ambiental; Acción local; Agenda 21

\footnotetext{
* Observatorio de Género, Economía, Políticas y Desarrollo. Grupo de investigación SEJ-507. Economía Ecológica, Feminista y Desarrollo de la Universidad Pablo Olavide. C.e: lauperezprieto@gmail.com.
} 
Lucca, E. (2016). La gestión de los territorios. La cosecha escondida o la percepción ambiental de los espacios. Buenos Aires: Diseño editorial

En el primer capítulo la autora nos introduce en la relación entre lo cultural humano y lo natural de una forma compleja, recordándonos que la contraposición cultura/naturaleza no existe como tal, y es más bien una estructura mental del pensamiento occidental, que tiende a organizar la realidad en base a categorías enfrentadas. La supuesta oposición "lógica" que establecemos entre naturaleza y cultura, carece para ella de sentido. En primer lugar, porque la naturaleza es una realidad biofísica incuestionable, pero también una construcción social, en tanto que somos los seres humanos los que le damos sentido y la significamos a través de nuestras prácticas discursivas; es decir, los que la experimentamos y teorizamos sobre ella en función de nuestras posiciones como individuos y colectivos, y de las normas sociales imperantes en cada etapa histórica. En segundo lugar, porque parte de lo que conocemos y pensamos nos llega a través de nuestras experiencias carnales, de nuestros sentidos y de nuestro contacto con el mundo que nos rodea (natural o antropizado).

A lo largo de la evolución se han ido dando procesos que nos han ido separando del resto de los seres vivos y nos han ido configurando como animales sociales, con capacidades únicas y con identidad propia. La aparición de nuestra parte "autónoma", no condicionada genéticamente, nos ha hecho posicionarnos como sujetos distintos a la naturaleza, no sometidos a su determinismo y con capacidad de elección; sin embargo, también nos ha predispuesto para ir olvidando nuestro propio motor biológico y nuestra pertenencia a la red de todo lo vivo, colocándonos en posiciones de dominación en las que no hemos dudado en explotar y mercantilizar el mundo natural, algo que ha ido contra la conservación de nuestra propia vida. La idea fundamental que la autora transmite en este capítulo es la de volver a estimular los instintos de supervivencia, las emociones, la afectividad y la relación con el otro (humano y no humano), reactualizando nuestro motor biológico con el objetivo de superar la dicotomía jerarquizada cultura/naturaleza y colocarnos en la interfase caótica cultura-naturaleza, un pasaje, un espacio, donde sea posible recrear la convivencia y reconstruirnos culturalmente desde la interrelación y la comprensión del otro.

En el capítulo 2 la autora nos explica sintéticamente en qué consiste el método de Percepción de los Espacios Naturales (PEA), que justamente tiene como objetivo el restablecimiento de esas relaciones entre los seres humanos y la naturaleza. Este método cualitativo pretende potenciar nuestra capacidad perceptiva a través del contacto con los espacios naturales y de la contemplación silenciosa del entorno, dejando emerger imágenes y visualizaciones creativas más que juicios previos, categorías mentales prefijadas y estructuras arcaicas de nuestro lenguaje que condicionan y limitan nuestra forma de entender el mundo. Una vez que demos tiempo suficiente para que emerjan estas nuevas vivencias y descubrimientos significativos en nuestro acercamiento al entorno, tenemos que apropiarnos de ellos, y luego, transmitirlos e intercambiarlos con el grupo a través de un lenguaje de emociones. Esto es, según Lucca, lo innovador del método, porque nos permite desarrollar otras formas de sentir y estar en nuestros entornos, otras formas de comunicar nuestras reacciones emocionales. Pero, además, conlleva un proceso colectivo, ya que lo emocional y personal se va compartiendo 
y se va creando una cultura grupal que predispone a otro tipo de acción, en este caso, una gestión sustentable de nuestros lugares y espacios de vida.

En el capítulo 3, la autora refleja su propio posicionamiento político con respecto a la sustentabilidad a partir de una serie de ideas fuerza. En primer lugar, argumenta que los territorios urbanos, los rurales y los naturales no se pueden gestionar ni pensar desde disciplinas separadas, pues son ecosistemas complejos que necesitan del continuo flujo de materiales y energías de los otros dos para autosustentarse. Por tanto, lo que existe es una interacción continua y una interdependencia que ha de ser abordada desde la transdisciplinariedad si pretendemos hablar de una gestión global sustentable.

Esta reflexión conecta con el propio concepto de sustentabilidad, y en concreto de la sustentabilidad fuerte, que es la que responde a los principios de la física y la ecología y que es la que promueve el respeto de todos los bienes, recursos y procesos biogeológicos necesarios para el desarrollo de la vida. La elasticidad, la regeneración y la estabilidad de los ecosistemas son fundamentales en este sentido. Sin embargo, debido a las "interferencias" que causamos los seres humanos guiados por la racionalidad económica imperante, también debemos hablar de capacidades perdidas que tenemos que rescatar para reconectarnos con las reglas del juego del ámbito natural, sin ejercer dominación. Esto no se consigue únicamente a través de una lectura analítica y sesuda del entorno, sino de la lectura perceptiva y emocional, que nos permita construir una racionalidad ecológica.

Lucca toma tres indicadores específicos como son la Huella Ecológica (HE), el Espacio Ambiental (EA) y los Indicadores de Captación Perceptiva (ICP) como forma de hacer medible cuantitativa y cualitativamente esa sostenibilidad, es decir, de mostrar el impacto de nuestras actividades, ofrecer una radiografía de nuestros problemas y abrir posibles vías para el cambio de conductas y comportamientos. Estos indicadores son una apuesta concreta por nuestra capacidad de transformar, de reaccionar y de inventar para responder sustentablemente al medio que nos rodea.

En el capítulo 4 se produce un ejercicio de concreción del concepto de sustentabilidad para generar una serie de principios operativos que puedan orientar las prácticas humanas, y que se alejen de la vaguedad y ambigüedad de la noción dominante de Desarrollo Sostenible. Para ello, introduce aspectos claves como una mirada holística que integre las dimensiones sociales, ambientales y económicas; la capacidad de negociación y diálogo para hacerlo posible; y, una organización social basada en redes de poder distintas a las hegemónicas. Frente a los mecanismos de disciplinamiento y control institucional/experto de todas las facetas de la vida y de la apropiación de los territorios y los recursos naturales, la autora nos habla de poner en marcha un esquema alternativo, un contrapeso basado en la participación radical, en la democracia directa y en la descentralización. Poder con los otros, no poder sobre los otros. Poder para implicarnos y tomar el control sobre lo que nos atañe, convivir y sustentarnos. Otras apuestas significativas que nos ofrece a lo largo del capítulo son:

- La generación de una ética del bienestar y de la sustentabilidad que ponga en cuestión el economicismo y la lógica acumuladora para centrarse en el respeto por la biodiversidad, en las relaciones económicas solidarias y locales, en el manejo de los recursos 
desde el reconocimiento de sus límites y en la reproducción social de la colectividad;

- La movilización de recursos sensitivos y relacionales como la creatividad, la capacidad de ayuda mutua o los conocimientos históricos de manejo de los recursos vitales;

- Una generalización de una idea de trabajo, no vinculada exclusivamente al empleo remunerado productor de mercancías, sino a una actividad propia de la naturaleza humana, necesaria para satisfacer las necesidades materiales y emocionales, vincularnos al territorio y movilizar energías sociales.

Por último, nos ofrece un instrumento para implementar esa visión de la sustentabilidad: la agenda local 21, una herramienta de partida muy potente a ojos de la autora que ayuda a defender esa autonomía local, modificar las relaciones de poder y las estructuras políticas convencionales.

En el capítulo 5 la escritora nos presenta brevemente la propuesta de aplicación para localidades de la provincia de Chaco, al nordeste de Argentina, definiendo para ello el problema a investigar, el enfoque y las referencias metodológicas utilizadas, los objetivos perseguidos, las fases y etapas previstas y las contribuciones que se esperan obtener con dicha propuesta práctica de gestión sustentable de los recursos naturales a través de la reapropiación de los espacios municipales. Esta parte es complementada por el capítulo 6, donde Lucca plantea de forma pormenorizada la investigación-acción con la que pretende evaluar en qué manera la implementación de un plan de acción en el que se aplica el método de percepción de los espacios municipales (naturales, urbanos y rurales), puede modificar pautas de convivencia, mentalidades, subjetividades, y generar capacidades humanas para la sustentabilidad. Las herramientas que propone consisten en una serie de esquemas compuestos por indicadores que sirven al equipo profesional y a las personas pobladoras para recoger la información descriptiva/analítica del territorio, la dimensión perceptiva de las comunidades y la dimensión de empoderamiento social de los grupos humanos sujetos de estudio. Además, brinda otras técnicas, como las entrevistas semiestructuradas y una encuesta final abierta para asegurarse de incorporar al máximo posible las opiniones y la parte de las relaciones territoriales de las personas involucradas en el trabajo.

Dentro de la dimensión descriptiva, incluye indicadores espaciales (tipos de ecosistemas, rol de cada uno de ellos, nivel de dependencia con respecto a los otros, estructura poblacional, etc.), ambientales (biodiversidad, agua, energía, residuos, etc.), sociales (pobreza, salud, vivienda, etc.) y de capacidad institucional para implementar la sustentabilidad. Dentro de la dimensión perceptiva, aborda indicadores sobre los modelos de interacción espacial, de percepción de los recursos o sobre los "contratos espaciales" que se contraen con el entorno. La dimensión de empoderamiento la mide la autora a través de la participación y la implicación de actores y actoras en la planificación, gestión y acción para la sustentabilidad.

En la tercera sección del libro (compuesta por el capítulo 7), una vez ofrecidos los datos sobre las problemáticas socioeconómicas y ambientales del municipio dentro de un contexto provincial y nacional signado por la desigualdad social y la sobreexplotación de los recursos naturales, se describen las distintas fases de la aplicación de la propuesta. En la fase propiamente de implementación, la más desarrollada en 
el capítulo, la autora nos va describiendo cómo las actividades desarrolladas con actores y actoras implicadas (caminatas perceptivas, mapeos, ejercicios de observación, visitas a los espacios forestales, agrícolas y urbano-productivos, revisión de la legislación o debates colectivos) van generando un autodiagnóstico de la zona, a la vez que un cuestionamiento sobre las pautas de comportamiento, y una mayor conciencia sobre el deterioro causado por la ganadería intensiva, el turismo masivo y la explotación forestal. Estos procesos vienen acompañados por un reconocimiento del valor de los recursos y saberes autóctonos para hacer una gestión sostenible y, finalmente, por un corolario de propuestas de las que todos y todas se sienten responsables y protagonistas. Lo que va reflejando es el camino de tránsito desde un enfoque centrado en los requerimientos de una sola especie a una mirada centrada en el sostenimiento de la vida-biosfera, que se materializa en la elaboración de una Carta Verde por parte de las personas pobladoras, es decir, en una batería de acciones y medidas para implementar.

En el capítulo 8, coincidente con la última sección del libro, la autora aporta una serie de conclusiones a partir del análisis de los datos recogidos: a pesar del alto porcentaje de ecosistemas naturales que posee la Isla de Cerrito y del espacio ambiental amplio disponible para cada habitante, existe una sistemática depredación de los recursos, una alta dependencia de los alimentos procedentes del exterior, una estructura económica débil, una huella ecológica por encima del promedio y una nula capacidad institucional para abordar planes y políticas de desarrollo sustentable. Esto se contrapone a lo que observa tras el proceso seguido con el método de PEA, donde comprueba que las personas pobladoras con las que se ha trabajado se encuentran movilizadas, empoderadas, activas y esperanzadas frente a las posibilidades de mejora que ellas mismas planifican y ponen en marcha.

En segundo lugar, expone algunos alcances y posibles limitaciones del proceso de cara a la consecución de objetivos ambientales, económicos, sociales, políticos y culturales marcados. Asimismo, hace referencia a los cambios producidos en cada uno de los actores implicados (municipalidad, equipo asesor, equipo coordinador, población sujeto, etc.) a través fundamentalmente de las entrevistas semiestructuradas realizadas. Algunas de las conclusiones obtenidas apuntan que:

- El grupo sujeto, tras descubrir una nueva forma de mirar el entorno (desde lo global y lo emocional), se desconcierta en un primer momento, pero retoma fuerza para encarar las acciones necesarias;

- El grupo conductor de trabajo y el de asesoría técnica se implican también en el proceso de sensibilización perceptiva y hacen una inmersión interdisciplinaria para poder asesorar y apoyar a la comunidad;

- Las experiencias "numínicas" o significativas obtenidas durante la fase de implementación del método llevan a la población a desarrollar un sentido crítico, una acción creativa y una visión común de lo que quieren para sus espacios de vida;

- La "cosecha escondida" de los y las participantes tiene que ver con el descubrimiento de lo desconocido y con el reencuentro con lo conocido desde unas coordenadas no explotadoras. Una experiencia liberadora en la que se incluye la autora, que transforma, junto a la comunidad, su manera de relacionarse con el territorio. 
En las conclusiones generales Lucca reflexiona sobre cómo la introducción del método PEA es, en realidad, una apertura del mundo de la gestión de la sustentabilidad, hacia metodologías cualitativas y herramientas perceptivas que tienen la capacidad de:

- Hacernos virar desde la mirada antropocéntrica, hacia una mirada relacional entre la cultura y la naturaleza, convirtiéndonos en seres conscientes de la interdependencia;

- Hacernos descubrir "la cosecha escondida" que existe en nosotros y nosotras y que implica sacar a la luz nuestra conexión con lo natural, con lo ecosistémico;

- Hacernos revisar nuestro propio concepto de sustentabilidad y anclarlo, ahora sí, a nuestra curiosidad, nuestra creatividad y nuestra inventiva para sostenernos respetando las dinámicas naturales;

- Crear un compromiso real de los grupos humanos con los espacios en los que habitamos;

- Generar instrumentos para las personas pobladoras, para que descubramos desde nuestra autonomía, la manera de caminar hacia la sustentabilidad, convirtiéndonos en actoras geógrafas de nuestro propio territorio.

Por último, encontramos en anexos, la Carta Verde de la Isla de Cerrito, elaborada por el grupo de personas pobladoras implicadas en el Plan de Acción hacia la sustentabilidad local (Agenda 21), que se desarrolla en el marco del convenio entre la Subsecretaría de Cultura de la provincia de Chaco y las autoridades municipales. En ella se incluye un documento base que articula acciones para reestablecer el equilibrio de los tres ecosistemas interdependientes: el espacio natural (dejando de ejercer presión y recuperando la masa boscosa), el espacio rural y productivo (recuperando formas de producción orgánicas y no contaminantes basadas en las capacidades de los habitantes) y el espacio urbano (frenando los focos de contaminación, reforestando y poniendo en marcha planes de educación ambiental). La carta cierra con los aportes del equipo asesor y coordinador para el manejo sustentable de los tres ecosistemas y con sus propuestas concretas para el control del crecimiento urbano, la valorización de las áreas paisajísticas y la formulación de una agenda ambiental con los puntos más relevantes a tener en cuenta.

Pérez Prieto, L. (2017). La Gestión de los Territorios. La cosecha escondida o la percepción ambiental de los espacios. Hábitat y Sociedad, 10, 349-354.

<http://dx.doi.org/10.12795/HabitatySociedad.2017.i10.21> 